Saudi Journal of Medicine

Abbreviated Key Title: Saudi J Med ISSN 2518-3389 (Print) |ISSN 2518-3397 (Online)

\title{
Impact of a Healthy Program on Weight Reduction using Social Media: A Voluntary Community-oriented Campaign through a Multidisciplinary Approach
}

\author{
Dr. Kawthar AlEid ${ }^{1 *}$, Ms. Areej Alsaad ${ }^{2}$, Dr. AbdulAziz Aljawder ${ }^{3}$, Dr. Adel Salman Al Sayyad ${ }^{4}$, Ms.Layla Almadani ${ }^{5}$
}

${ }^{1}$ Consultant family medicine \& health promotion, Ministry of Health, Bahrain

${ }^{2}$ Clinical dietician, King Hamad Hospital, Bahrain

${ }^{3}$ Demonstrator in the Department of Physiology, Arabian Gulf University, Bahrain

${ }^{4}$ Consultant family medicine \& epidemiology, Ministry of Health, Bahrain

${ }^{5}$ Physiotherapist, Ministry of Health, Bahrain

DOI: $10.36348 / \mathrm{sjm} .2019 . \mathrm{v} 04 \mathrm{i} 12.005$

| Received: 11.12.2019 | Accepted: 20.12.2019 | Published: 26.12.2019

*Corresponding author: Dr. Kawthar Mohammad AlEid, MD, ABFM

\section{Abstract}

Aim: To assess the effects of a voluntary, community-oriented campaign using social media through a multidisciplinary approach on body weight. Setting and Design: A survey, community-oriented using popular social media accounts. Methods: 268 followers from the community participated in the study using a questionnaire, which was constructed by a study group and self-filled online using google drive. Results: A total of 268 followers participated in the study. A healthy program had been applied by $43.3 \%$ of the survey respondents, consisting of a unified healthy diet and mildmoderate intensity exercises for less than a year, while only $13.1 \%$ applied it for more than a year. Almost half the survey respondents $(48.5 \%$ ) followed the campaign for less than one year, and $41.8 \%$ for more than one year. There were changes in diet and nutritional habits on the followers, after following/applying the healthy program. Their habit of practicing physical activities was improved. The voluntary community campaign raised awareness among participants and produced positive psychological eating behavioral changes. Conclusion: There was a significant difference in weight reduction after following the healthy program for more than one year and to a lesser extent for those who followed it for less than one year.

Keywords: Healthy program, campaign, voluntary, weight reduction, physical activity, diet, nutrition, psychological health, social media.

Keymessages: Overweight and obesity are two of the most common biological risk factors that lead to noncommunicable diseases, which have resulted in the need for targeted preventative interventions becoming almost mandatory. Literature that aim to modify communities' lifestyles positively, through social media are lacking locally, regionally and internationally.

Copyright @ 2019: This is an open-access article distributed under the terms of the Creative Commons Attribution license which permits unrestricted use, distribution, and reproduction in any medium for non-commercial use (NonCommercial, or CC-BY-NC) provided the original author and source are credited.

\section{INTRODUCTION}

Being overweight and obese is defined as abnormal or excessive fat accumulation that can present health risks. A crude population measure of obesity is the body mass index (BMI), a person's weight in kilograms divided by the square of his/her height in meters [1]. BMI is a measure of body size based on weight in relation to height. Values between 18.5 and 24.9 are considered optimum; less than 18.5 is underweight and between 25 and 29.9 is overweight. A BMI more than or equal to $30 \mathrm{~kg} / \mathrm{m} 2$ is considered obese. Obesity is further sub classified into degrees: Mild obesity has a BMI between 30 and 34.9, moderate obesity between 35 and 39.9, morbid obesity between 40 and 59.9 and super obesity is more than 50 [1].

The prevalence of obesity has nearly tripled between 1975 and 2016 worldwide [2], in terms of which considerations regarding public health have become significant; one of the highest rates of obesity is seen in the Uniteda States [3]. Lots of deaths almost 3.4 million have been caused due to obesity or being overweight, based on findings published in "The Lancet" in 2014. Being overweight and obesity rates have increased by $27.5 \%$ in adults and by $47.1 \%$ in children, since 1980. According to this article, no country worldwide has succeeded in decreasing obesity among their population in the last 33 years [4]. 
Over the past two decades, the Kingdom of Bahrain has reported a rise in the records of obesity among its adult population, according to a crosssectional study on 414 volunteers from a local shopping mall. The rates detected were $37 \%$ and $30 \%$ for females and males, respectively [5]. During the past 40 years, the prevalence of obesity has grown alarmingly in Bahrain, as a consequence of significant developments in the economy resulting from rich deposits of oil reserves and the influence of rapid urbanization and improved living conditions [6]. In 2010, the prevalence of obesity in Bahrain was $21 \%$ and $38 \%$ for males and females, respectively [6]. With modernization, the people of Bahraini people have become inactive and have gained unhealthy nutritional habits.

Weight loss of 5 to $10 \%$ within 6 months can promote health improvements, such as reduction in triglycerides and glycemic levels (which reduce the risk of developing diabetes). Besides, weight loss can reduce the risk of coronary vascular diseases by improving low-density and high-density lipoprotein cholesterol and blood pressure [7].

There is scientific evidence suggesting that multidisciplinary programs and teams produce and sustain moderate weight loss (between 5 to $10 \%$ ) for the long term. These teams consist of a physician, a psychologist, a physical therapist, and a dietician [8]. Another study examined the effects of a tailored lifestyle intervention-including face-to-face diet instructions and physical activities - on body weight in $(n=211)$ sedentary obese participants, for a period of 24 months. The study revealed significant weight loss in the intervention group, with loss of about $5 \%$ of their baseline weight during the first 6 months $(37.2 \%$ vs $12.9 \%)$, with the impacts peaking for only 12 months (47\% vs $11.9 \%$ )[9]. Moreover, a systematic review of 17 randomized controlled trials (RCTs) focused on the impact of lifestyle modifications, including diets, physical activities, and behavioral therapy, for weight loss in obese adults, for a period of 12 weeks. 14 out of these 17 RCTs showed that these lifestyle modifications had a great impact on weight reduction, compared to participants in the control group for all studies (1.0$11.5 \mathrm{~kg}$ ) [10].

A study analyzed the influence of communitybased physical activities, nutrition and behavior intervention on reducing the risk of metabolic syndrome among $(n=418)$ overweight and obese adults in Vietnam, who were randomly assigned, in 10 community centers in Vietnam, over a period of 6 months. The study revealed significant enhancement in high-density lipoprotein cholesterol (HDL) $(-0.024, \mathrm{P}<$ $0.001)$, weight $(-1.44 \mathrm{~kg}, \mathrm{P}<0.001)$, body mass index $(-0.59 \mathrm{~kg} / \mathrm{m} 2, \mathrm{P}<0.001)$, waist circumference $(-1.63$ $\mathrm{cm}, \mathrm{P}<0.001)$, and waist-to-hip ratio $(-0.024, \mathrm{P}<$ 0.001 ) in contrast to control group [11].
One study looked at the effects of a community-based weight management program on weight loss and cardiovascular disease risk factors. 418 obese and overweight subjects were included. A 6month program consisting of a dietary program (1200 $1800 \mathrm{kcal} / \mathrm{day}$ ), focusing on fruits, vegetables and lowfat dairy, cardiovascular and aerobic exercises and strength training was employed. The participants lost around $4.7-7.3 \%$ of their body weight, with improved fasting lipids and blood glucose levels [12].

A systematic review of internet and mobile interventions for improving diet, physical activity, obesity, and tobacco and alcohol use researched 224 studies, of which 20 involved improved diets, 33 physical activity, 35 fat mass, 22 tobacco use and 47 excess alcohol use. It was concluded that internet and mobile interventions improved lifestyle behavior up to one year [13].

The American Psychological Association (APA) has stated that genetic factors, prolonged overeating or a sedentary lifestyle are rarely causes of obesity[14].What an individual does and does not do often results from their cognitive beliefs, which in turn, influences their behavior. To succeed in the long-term treatment of obesity, we have to consider psychosocial and psychopathological determinants. The reasons behind this is that several factors, such as being overweight and self-esteem, mood disorders, eating disorders, life events, and anxiety and personality disorders, have significant correlations[15, 16].

Being overweight and obesity, as results of sedentary lifestyles, unhealthy diets and stressful life conditions, are the most common biological risk factors that result in non-communicable diseases, making mandatory the need for targeted preventive interventions among vulnerable population in the community [17]. Literature that aim to modify communities' lifestyle positively through social media, with a healthy program, are lacking locally, regionally and internationally; therefore, we decided to undertake this study to assess the effects of a voluntary community-oriented campaign using social media, through a multidisciplinary approach on body weight. It is one of the fewer community campaigns, held voluntarily through social media in Bahrain, by a group of professionals, to combat obesity to achieving a part of the third sustainable developmental goal (SDG). The WHO has stated, "SDG 3: Ensure healthy lives and promote wellbeing for all at all ages", and one of the goals within this goal involves health targets for SDG 3-“3.4: By 2030, reduce by one third premature mortality from non-communicable diseases through prevention and treatment and promote mental health and well-being [18]". 


\section{METHODS}

A survey was conducted involving the voluntary community campaign's social media followers, mainly on Instagram $(n=17200)$, and other social media accounts; Facebook $(\mathrm{n}=1061)$, Snapchat $(\mathrm{n}=900)$, WhatsApp $(\mathrm{n}=653)$, and recently, Twitter ( $\mathrm{n}$ $=49$ ). The campaign was launched voluntarily in March 2018, by a group of experts in health promotion, nutrition, sports and psychological health. The voluntary community campaign's theme is "Obesity doesn't suit me," and its long-term objective is to reduce obesity among its followers on various social media accounts, to prevent or reduce the incidence of non-communicable diseases by maintaining the ideal weight (BMI between 18.5 to 24.9). It also aims to encourage the followers in the community to adopt healthy lifestyles, such as healthy diets and daily physical activities through social media, and thus, achieving the third sustainable development goal and Bahrain's Vision 2030. The followers began to interact with the campaign's components by adopting healthy lifestyles, such as daily physical activities and a healthy diet. They were assigned to a healthy diet plan, exercises and psychological health tips, designed for the followers mainly on the Instagram account (@drkawthar_aleid).

A questionnaire was created by the professional team and tested on 30 followers. It included the following variables; Demographic data (age, sex, nationality, residency, educational level, financial level and employment), following and or applying the campaign's component, weight before and after the healthy program, nutrition section, physical activity section, and psychological health section. All participants were asked to complete this selfadministered online questionnaire after more than one year of initiating the healthy program, and it was kept anonymous. The respondents were asked to answer the survey freely, or they could choose to skip it entirely. 268 voluntarily completed the survey within almost three weeks, from 28 May 2019 to 21 June 2019, while all the followers for the campaign were encouraged to respond and answer it. An instruction about filling the questionnaire was provided with it, and each questionnaire was assigned a special identity number for referencing and was coded for data entry and processing. Data was entered into a database program (SPSS) and frequency tables with percentages were generated.

The healthy program consisted of three main components: exercise, diet and psychological health, which are explained as follows:

\section{Exercise program}

Due to the fact that the whole study was mostly social media-oriented, in-person interviews and physical tests for fitness level evaluation were not implemented. The only evaluation test that was utilized was the "WHO Global Physical Activity Surveillance," which is a questionnaire that aims to survey physical activity levels among the population, using a standardized protocol. It covers several components of physical activity, such as intensity, duration, and frequency, and it assesses three domains in which physical activity is performed (occupational physical activity, transport-related physical activity, and physical activity during discretionary or leisure time)[18]. The exercise program was constructed by a certified personal trainer, who is also one of the authors. The program consisted of one instructional video and three beginner exercise routines that required only an optional exercise mat and a bottle of water, used for resistance and targeting the cardiovascular system and the whole-body musculature. The instructional video explained the safety precautions and provided an overview of the WHO exercise recommendations for healthy adults. The videos were uploaded to a YouTube channel under the title "Obesity does not suit me," and they were made accessible to everyone. All safety measures were thoroughly explained during each video to avoid any complications, such as dehydration and musculoskeletal injuries.

The

https://m.youtube.com/channel/UCdSkghfQtMgrIsSYJ q5F6vg

\section{Diet plan}

Our diet plan-designed with moderate caloric restriction at $1500 \mathrm{kcal} /$ day and based on our Bahraini traditional dishes - targeted the adult community, focusing on individuals without diet counselling, to help them meet their safe caloric restrictions and ideal nutritional requirements. The American Dietetic Association recommends that in order to achieve and maintain nutrient adequacy and reduce caloric intake, the following caloric restriction strategies should be followed: $1200 \mathrm{Kcal}-1500 \mathrm{kcal} / \mathrm{day}$ for females and $1500 \mathrm{Kcal}-1800 \mathrm{kcal}$ for males [19]. We utilized the influence of social media to guide the community about the benefits of healthy eating, healthy grocery shopping, healthy cooking methods, and tips on how to measure and control food portion sizes.

\section{Psychological eating behavior}

For the followers on the social media accounts, primarily Instagram, three key mental health awareness posts related to combating obesity were created from the summary session of 10 participants, who were curated from the followers and chosen at random. They were screened for psychological conditions such as depression and eating disorders (which have a strong relationship with obesity). All these posts were made accessible to everyone on the social media accounts A three-page long psychological questionnaire was designed to further inspect areas of self-image, selfworth, eating habits, activity level, self-harm, cognition and perception. It was crucial to screen the participants 
for unhealthy habits and unhealthy thoughts which triggered a condition of overeating. If left unrecognized and untreated, these triggers will eventually cause the participants to gain weight during and/or after the campaign.

The answers of each participant was then coded and used for further investigation in a one-on-one consultation with the psychologist. During the consultation, each participant was able to discuss their history, current condition and future goals to create a realistic perception and start a new plan, challenging both thoughts and behaviors that support the new vision. Following up the consultation session, the participants received individual treatment plans to help them manage thoughts, feelings and behaviors connected to obesity.

\section{RESULTS}

A total of 268 followers participated in the study. The mean age and standard deviation of the survey respondents was $38.12 \pm 9.97$, while the range age was between 18 and 65 years old, but the sample was normally distributed. The participants had been divided into five subgroups, and the majority of them were between the ages 31 to 40 years. A majority $(89.9 \%)$ of the survey respondents were Bahraini and (94\%) of them were living in Bahrain. Most of survey respondents $(70.5 \%)$ were university graduates, a few of them $(27.6 \%)$ were high school graduates and only $(1.9 \%)$ could just read and write. Moreover, $60.1 \%$ of the survey respondents were employees, housewives (19.4\%), unemployed (16\%) and students (4.5\%). Additionally, $70.9 \%$ of the survey respondents were of a moderate financial status, whereas $22 \%$ were from high and $7.1 \%$ were from low ranges (Table 1 ). The results showed that $43.3 \%$ of the survey respondents had applied the healthy program for less than one year, while $13.1 \%$ had only applied it for more than one year. $48.5 \%$ of the survey respondents had followed the campaign for less than one year, and $41.8 \%$ for more than one year (Table 2).

\section{The nutrition section}

The results showed that there were changes in diet and nutrition habits on the followers after following/applying the healthy program. The biggest change was noted participants $(43.3 \%)$ were eating a quarter of a healthy plate of carbs for their main meals, which is considered a healthy habit, while the least change was seen in the avoidance of adding sugar to beverages and food, which was about $10.4 \%$. The healthy behaviors of diet and nutrition habits improved after following/applying the healthy program in the consumption of boiled or grilled food, low salt food items, vegetables and fruits, and low fat foods to $32.1 \%$, $31 \%, 29.9 \%, 28.4 \%$, respectively. In addition, the consumption of a quarter of a healthy plate of protein and meat in the main meals increased to $39.6 \%$, while only $23.1 \%$ changed their dairy products consumption and $25 \%$ their whole grain food consumption, but few followers added alternative sweetener to their beverages and food $(20.1 \%)$. The consumption of water daily, after following/applying the healthy program, increased to $26.1 \%$ (Table 3 ).

\section{The physical activity section}

The results showed that $28.7 \%$ of participants practiced mild to moderate intensity physical activities for half an hour, five times a week, after following/applying the heathy program, while $36.9 \%$ were already doing the same level of physical activity before following the program; which meant that the percentage of practicing physical activities was improved. Additionally, the number of participants who practiced moderate to vigorous exercise for 20 minutes, three times a week, had doubled to 128 , before and after following/applying the heathy program (Table 4).

\section{Psychological eating behavior section}

The voluntary community campaign raised awareness of psychological eating behaviors and produced positive changes among participants, after following/applying the healthy program. The results showed that $48.9 \%$ participants knew that weight gain was related to food addiction. Moreover, after following/applying the healthy program, the moods changed positively in $57.1 \%$ of survey respondents, and $74.6 \%$ of survey respondents were aware of eating disorders and could differentiate between them and knew the health hazards. The healthy program had a positive effect on cognitive behaviors, thoughts and feelings, such that about $70.1 \%$ of the participants following/applying it had committed to the healthy diet and physical activity programs (Table 5).

\section{The Impact of the Healthy Program on Weight Reduction after Applying and Following the Program in the Campaign}

There were significant changes in weight reduction in participants following/applying the healthy program. The mean and standard deviation of weight before and after the healthy program were 86.01 \pm 18.266 and $78.82 \pm 16.474$, respectively (Table 6). There were 58 participants who did not apply the program, and did not answer the measurement of the weight, before and after the program; thus, their answers were treated as missing values before testing the relation between the weight and health program (Tables 7 and 8). Paired samples test results showed that the mean weight and standard deviation for the 109 survey respondents were $84.6 \pm 15 \mathrm{~kg}$, and there was a significant difference after following the healthy program for less than one year. The results showed that there was about a six kilogram reduction of their body weight. The mean weight and standard deviation for the 85 survey respondents were $86.9 \pm 21 \mathrm{~kg}$, and there was a significant reduction to $77.3 \pm 16 \mathrm{~kg}$ after applying the healthy program for more than one year. On the one hand, there was no significant change in the weight of 
the non-followers (Table 7). Moreover, the mean weight and standard deviation for the 115 survey respondents was $86.6 \pm 17 \mathrm{~kg}$, and there was significant reduction to $78.5 \pm 14 \mathrm{~kg}$ after applying the program for less than one year. The reduction in weight was obvious in the group who followed and applied the program for a year and more, the mean weight and standard deviation for the 32 survey respondents was $84.3 \pm 21.2$ $\mathrm{kg}$, and there was a significant reduction to $72.9 \pm 15.9$ $\mathrm{kg}$ after applying the program for more than one year. On the other hand, there was a significant change in weight for the non-applicants of about three kilograms (Table 8).

Table-1: Demographic data of participants following/applying the healthy program in the campaign

\begin{tabular}{|c|c|c|c|}
\hline \multicolumn{2}{|c|}{ Variable } & No & $\%$ \\
\hline \multirow[t]{2}{*}{ Gender } & Male & 63 & 23.5 \\
\hline & Female & 205 & 76.5 \\
\hline \multirow[t]{4}{*}{ Age group } & $<30$ & 63 & 23.5 \\
\hline & $31-40$ & 101 & 37.7 \\
\hline & $41-50$ & 74 & 27.6 \\
\hline & $>51$ & 30 & 11.2 \\
\hline \multirow[t]{2}{*}{ Nationality } & Bahraini & 241 & 89.9 \\
\hline & Non Bahraini & 27 & 10.1 \\
\hline \multirow[t]{2}{*}{ Residence } & Bahraini & 252 & 94 \\
\hline & Non Bahraini & 16 & 6 \\
\hline \multirow[t]{3}{*}{ Education level } & Read and Write & 5 & 1.9 \\
\hline & High school & 74 & 27.6 \\
\hline & University graduate & 189 & 70.5 \\
\hline \multirow[t]{4}{*}{ Occupation } & Student & 12 & 4.5 \\
\hline & Housewife & 52 & 19.4 \\
\hline & Employee & 161 & 60.1 \\
\hline & Unemployed & 43 & 16.0 \\
\hline \multirow[t]{3}{*}{ Financials status } & Low & 19 & 7.1 \\
\hline & Moderate & 190 & 70.9 \\
\hline & High & 59 & 22 \\
\hline
\end{tabular}

Table-2: Number of participants following / applying the healthy program in the campaign

\begin{tabular}{|l|c|c|c|c|c|c|}
\hline \multirow{2}{*}{ Variable/Responses } & \multicolumn{2}{c|}{ Less than one year } & \multicolumn{2}{c|}{ More than one year } & \multicolumn{2}{c|}{ I didn't follow } \\
\cline { 2 - 7 } & No & $\boldsymbol{\%}$ & No & $\%$ & No & \% \\
\hline Period of the applying the healthy program & 116 & 43.3 & 35 & 13.1 & 117 & 43.7 \\
\hline Period of following the healthy program & 130 & 48.5 & 112 & 41.8 & 26 & 9.7 \\
\hline
\end{tabular}

Table-3: The Diet/Nutrition Section

\begin{tabular}{|c|c|c|c|c|c|c|}
\hline \multirow[t]{2}{*}{ Variable/Responses } & \multicolumn{2}{|c|}{$\begin{array}{c}\text { Yes before } \\
\text { following/appl } \\
\text { ying the } \\
\text { healthy } \\
\text { program } \\
\end{array}$} & \multicolumn{2}{|c|}{$\begin{array}{c}\text { Yes after } \\
\text { following/ap } \\
\text { plying the } \\
\text { healthy } \\
\text { program }\end{array}$} & \multicolumn{2}{|c|}{ No } \\
\hline & No & $\%$ & No & $\%$ & No & $\%$ \\
\hline $\begin{array}{l}\text { I have one serving of fruits and vegetables for main meals } \\
\text { or snacks }\end{array}$ & 122 & 45.5 & 80 & 29.9 & 66 & 24.6 \\
\hline I eat quarter plate of carbohydrates/grains for main meals & 85 & 31.7 & 116 & 43.3 & 67 & 25.0 \\
\hline I eat quarter plate of protein and meat for main meals & 118 & 44.0 & 106 & 39.6 & 44 & 16.4 \\
\hline I have dairy products three times per day & 71 & 26.5 & 62 & 23.1 & 135 & 50.4 \\
\hline I drink eight cups of water per day & 121 & 45.1 & 70 & 26.1 & 77 & 28.7 \\
\hline I have low-fat food & 123 & 45.9 & 76 & 28.4 & 69 & 25.7 \\
\hline I have boiled or grilled food & 121 & 45.1 & 86 & 32.1 & 61 & 22.8 \\
\hline I have whole grain food & 122 & 45.5 & 67 & 25.0 & 79 & 29.5 \\
\hline I have low salt food & 107 & 40.7 & 83 & 31.0 & 76 & 28.4 \\
\hline I don't add sugar to beverages and food & 111 & 41.4 & 28 & 10.4 & 12 & 48.1 \\
\hline I add alternative sweeteners to the beverages and food & 58 & 21.6 & 54 & 20.1 & 156 & 58.2 \\
\hline
\end{tabular}


Table-4: The Physical Activity Section

\begin{tabular}{|c|c|c|c|c|c|c|}
\hline \multirow[t]{2}{*}{ Variable / Responses } & \multicolumn{2}{|c|}{$\begin{array}{c}\text { Yes before following/ applying } \\
\text { the healthy program }\end{array}$} & \multicolumn{2}{|c|}{$\begin{array}{c}\text { Yes after following/ applying } \\
\text { the healthy program }\end{array}$} & \multicolumn{2}{|c|}{ No } \\
\hline & No & $\%$ & No & $\%$ & No & $\%$ \\
\hline $\begin{array}{l}\text { Mild and simple }- \text { physical activity for } \\
\text { half an hour, five times per week }\end{array}$ & 99 & 36.9 & 77 & 28.7 & 92 & 34.4 \\
\hline $\begin{array}{l}\text { Moderate to vigorous-physical } \\
\text { activity for } 20 \text { mins, three times per } \\
\text { week }\end{array}$ & 65 & 24.3 & 63 & 23.5 & 140 & 52.2 \\
\hline
\end{tabular}

Table-5: The Psychological Eating Behavior Section

\begin{tabular}{|c|c|c|c|c|c|c|}
\hline \multirow[t]{2}{*}{ Variable/Responses } & \multicolumn{2}{|c|}{ Yes } & \multicolumn{2}{|c|}{ No } & \multicolumn{2}{|c|}{ Not applicable } \\
\hline & No & $\%$ & No & $\%$ & No & $\%$ \\
\hline Weight gain related to food addiction & 131 & 48.9 & 99 & 36.9 & 38 & 14.2 \\
\hline Mood change after following/applying the healthy program & 153 & 57.1 & 42 & 15.7 & 73 & 27.2 \\
\hline $\begin{array}{l}\text { Differentiating between the behaviour of excessive eating and } \\
\text { other eating disorders as well as the consequences of both on the } \\
\text { human body and mind }\end{array}$ & 200 & 74.6 & 43 & 16.0 & 25 & 9.3 \\
\hline $\begin{array}{l}\text { Participants' thoughts and feelings affecting their eating } \\
\text { behaviour and commitment to a healthy diet }\end{array}$ & 188 & 70.1 & 15 & 5.2 & 66 & 24.6 \\
\hline
\end{tabular}

Table-6: Weight before and after following/applying the healthy program

\begin{tabular}{|r|c|c|c|c|c|c|c|}
\hline Variable & Mean & $\begin{array}{c}\text { Std. } \\
\text { Deviation }\end{array}$ & Median & Mode & $\begin{array}{c}\text { Difference in } \\
\text { means }\end{array}$ & $\begin{array}{c}\text { P- } \\
\text { Value }\end{array}$ \\
\hline $\begin{array}{r}\text { Weight before } \\
\text { following/applying the } \\
\text { healthy program }\end{array}$ & 86.01 & 18.266 & 82.00 & 72 & 7.19 & \multirow{2}{*}{8.36} & 0.000 \\
$\begin{array}{r}\text { Weight after } \\
\text { following/applying the } \\
\text { healthy program }\end{array}$ & 78.82 & 16.474 & 75.00 & 70 & & \\
\hline
\end{tabular}

Table-7: Paired Samples Test Statistics for the participants following the healthy program

\begin{tabular}{|c|c|c|c|c|c|c|c|c|}
\hline \multicolumn{3}{|c|}{$\begin{array}{ll}\text { Variable } \\
\end{array}$} & \multirow{2}{*}{$\begin{array}{l}\text { Mean } \\
84.58\end{array}$} & \multirow{2}{*}{$\begin{array}{c}\text { No } \\
109 \\
\end{array}$} & \multirow{2}{*}{$\begin{array}{c}\begin{array}{c}\text { Std. } \\
\text { Deviation }\end{array} \\
14.967\end{array}$} & \multirow{2}{*}{$\begin{array}{c}\begin{array}{c}\text { Difference } \\
\text { in Mean }\end{array} \\
5.99\end{array}$} & \multirow{2}{*}{$\begin{array}{c}\% \\
7.08\end{array}$} & \multirow{2}{*}{$\begin{array}{c}\text { P-Value } \\
0.000\end{array}$} \\
\hline Follow less & Pair 1 & Weight before & & & & & & \\
\hline than one year & & Weight after & 78.59 & 109 & 14.748 & & & \\
\hline \multirow{2}{*}{$\begin{array}{l}\text { Follow more } \\
\text { than one year }\end{array}$} & \multirow[t]{2}{*}{ Pair 1} & Weight before & 86.88 & 85 & 20.801 & \multirow[t]{2}{*}{9.56} & \multirow[t]{2}{*}{11.03} & \multirow[t]{2}{*}{0.000} \\
\hline & & Weight after & 77.32 & 85 & 16.429 & & & \\
\hline \multirow[t]{2}{*}{ I didn't follow } & \multirow[t]{2}{*}{ Pair 1} & Weight before & 91.21 & 16 & 23.762 & \multirow[t]{2}{*}{2.81} & \multirow[t]{2}{*}{3.08} & \multirow[t]{2}{*}{0.127} \\
\hline & & Weight after & 88.40 & 16 & 24.341 & & & \\
\hline
\end{tabular}

Table-8: Paired Samples Test Statistics for the participants applying the healthy program

\begin{tabular}{|c|c|c|c|c|c|c|c|c|}
\hline \multicolumn{3}{|c|}{ Variable } & \multirow{2}{*}{\begin{tabular}{|c|}
$\begin{array}{c}\text { Mea } \\
\text { n }\end{array}$ \\
86.75 \\
\end{tabular}} & \multirow{2}{*}{\begin{tabular}{|l|} 
No \\
115 \\
\end{tabular}} & \multirow{2}{*}{$\begin{array}{c}\begin{array}{c}\text { Std. } \\
\text { Deviation }\end{array} \\
17.088 \\
\end{array}$} & \multirow{2}{*}{$\begin{array}{c}\begin{array}{c}\text { Difference } \\
\text { in Mean }\end{array} \\
8.29\end{array}$} & \multirow{2}{*}{$\begin{array}{c}\% \\
9.56\end{array}$} & \multirow{2}{*}{$\begin{array}{c}\text { P-value } \\
0.000\end{array}$} \\
\hline \multirow{2}{*}{$\begin{array}{r}\text { Apply less than } \\
\text { one year }\end{array}$} & \multirow[t]{2}{*}{ Pair 1} & Weight before & & & & & & \\
\hline & & Weight after & 78.46 & 115 & 14.123 & & & \\
\hline \multirow{2}{*}{$\begin{array}{l}\text { Apply more } \\
\text { than one year }\end{array}$} & \multirow[t]{2}{*}{ Pair 1} & Weight before & 84.28 & 32 & 21.245 & \multirow[t]{2}{*}{11.36} & 13.4 & \multirow[t]{2}{*}{0.000} \\
\hline & & Weight after & 72.92 & 32 & 15.853 & & 8 & \\
\hline \multirow[t]{2}{*}{ I didn't apply } & \multirow[t]{2}{*}{ Pair 1} & Weight before & 85.55 & 63 & 18.955 & \multirow[t]{2}{*}{3.07} & \multirow[t]{2}{*}{3.59} & \multirow[t]{2}{*}{0.000} \\
\hline & & Weight after & 82.48 & 63 & 19.764 & & & \\
\hline
\end{tabular}

\section{DISCUSSION}

This study showed that there was a significant reduction in weight after applying the healthy program for more than year, and the reduction was obvious among these participants. The results also showed that those who applied the healthy program for less than one year and those who didn't apply it at all saw significant but lesser reductions, compared to those who applied it for more than one year. The significant reduction in weight after applying the healthy program for more than year was almost similar to another study, which revealed that multidisciplinary programs produced and sustained moderate weight loss between 5 to $10 \%$ for the long term [8]. There was also a significant difference after following the program for less than one year, the results showed that there was about a six kilogram reduction of their body weight, which is almost similar to that results found in another study, which showed a weight loss of 5 to $10 \%$ over 6 months[7]. The results of our study also showed that 
there was a change in diet habits and nutrition healthy components for the followers who followed and applied the healthy program; similar to the systematic review of the internet and mobile interventions for improving diet, physical activities, obesity, and tobacco and alcohol use [13]. Those who didn't follow the healthy programs also lost three kilograms and that might be due to other healthy programs, as stated by some of the followers. However, the highest score in weight reduction was found in those who applied the healthy program for more than year. The adoption of healthy lifestyles after following a healthy program was obvious among participants, such as practicing daily physical activities, improving psychological health, engaging in healthy diets and nutrition, according to the healthy plate. Literature showed that unhealthy, mindless eating habits can be changed effectively through mindfulness-based interventions [20].

The followers in this study appreciated the free of charge healthy program on social media, with continuous counseling and monitoring, making it an easy, accessible and affordable healthy program. On the other hand, they asked to provide a place for direct, face-to-face consultations but that was beyond the campaign's scope. Therefore, we guided them to centers that provide healthy programs with minimal charges. The campaign will offer its awareness and behavioral modification services on a regular basis, with a greater focus on areas of improvement and limitations.

\section{LIMITATIONS}

The campaign's materials and posts were in Arabic language only, and we will consider other languages in the future, once we have settled with team members. We could not know for sure that the participants followed the exercise program along with the nutritional plan, because the whole program was on social media and not personalized and/or directly monitored. Moreover, regarding the exercise section, there were only three recorded exercise videos on YouTube, so the participants might have gotten bored doing the same exercises multiple times? In addition, the results of weight loss among the participants could be the cause of other interventions, not provided by our program, such as dietary supplements, surgical operations, drugs etc., and some of the results could be old results, not gained using our program with its duration. No long term data on maintenance of weight loss. Objective data were self-reported (weight). There was no BMI data or waist circumference. Finally, we couldn't consider the measurement of biological factors as a component of the healthy program, such as blood pressure or blood glucose level or lipid profile. During our follow-up and monitoring of the direct messages from the participants on social media, we noticed that the followers' biological factors had improved.

\section{CONCLUSION}

There was a significant difference in weight reduction after following the program for less or more than one year, and for the non-applicants' group. Moreover, the best significant differences in weight reduction after following the program was seen in those participants who followed and applied the healthy program for more than one year, and less in those who followed and applied the healthy program for less than one year as well as the non-applicants' group. The effect of the voluntary community campaign on weight reduction using the social media was significant. Its sustainability can be considered with more focus on the areas of improvement and limitations.

\section{ACKNOWLEDGEMENT}

We would like to show gratitude to clinical psychologist Maha Almannai, for providing insight about psychological eating disorders. We would also like to thank professional photographer Mohsin Alaali, for capturing and recording all the pictures and videos pertaining to the research. Also credits to social media specialist Mona Haji, for managing the Instagram account of the campaign. Last and not the least, our gratitude to His Excellency Lieutenant General Sheikh Mohammed bin Abdullah Al Khalifa, Chairman of the Supreme Council of Health in Kingdom of Bahrain for his continuous support for the campaign.

\section{REFERENCES}

1. WHO .Obesity. (Cited May 4, 2019). Available from https://www.who.int/topics/obesity/en/

2. World Health Organization. (2018). Obesity and overweight. World Health Organization.2018. (Cited Sep 3, 2019). Available from https://www.who.int > news-room > fact-sheets > detail > obesity-and-overweight.

3. Arroyo-Johnson, C., \& Mincey, K. D. (2016). Obesity epidemiology worldwide. Gastroenterology Clinics, 45(4), 571579.

4. Ng, M., Fleming, T., Robinson, M. (2013). Global, regional, and national prevalence of overweight and obesity in children and adults during 19802013: a systematic analysis for the Global Burden of Disease Study 2013. The Lancet. 2014 Aug 30; 384 (9945):766-781. (Cited May 4, 2019). Available from https://doi.org/10.1016/S01406736(14)60460-8

5. Jaoua, N., Woodman, A., \& Amini, M. (2018). Abnormal Weight among University Students in the Kingdom of Bahrain: Prevalence, Factors, Predictions, and Recommendations. Unpublished, University of Bahrain.

6. AL, Nohair, S. (2014). Obesity in gulf countries. International journal of Health Science, 8(1):79-83.

7. Franz, M., MacLeod, J., \& Evert A., Brown, C., Gradwell, E., Handu, D., Reppert, A., \& Robinson, M. (2017). Academy of Nutrition and Dietetics Nutrition Practice Guideline for Type 1 and 
Type 2 Diabetes in Adults: Systematic Review of Evidence for Medical Nutrition Therapy Effectiveness and Recommendations for Integration into the Nutrition Care Process. Journal of the Academy of Nutrition and Dietetics, 10(117), 1659-1679.

8. Hamdy, O., Uwaifo, G., Oral E. (2018, March 30). What are the ACC, the AHA, and TOS treatment guidelines for obesity and one or more comorbidities? (Cited May 4, 2019). Available from https://www.medscape.com/answers/12370211539/what-are-the-acc-the-aha-and-tostreatmentguidelines-for-obesity-and-one-or-morecomorbiditie

9. Eaton, C. B., Hartman, S. J., Perzanowski, E., Pan, G., Roberts, M. B., Risica, P. M., \& Marcus, B. H. (2016). A randomized clinical trial of a tailored lifestyle intervention for obese, sedentary, primary care patients. The Annals of Family Medicine, 14(4), 311-319.

10. Hassan, Y., Head, V., Jacob, D., Bachmann, M. O., Diu, S., \& Ford, J. (2016). Lifestyle interventions for weight loss in adults with severe obesity: a systematic review. Clinical obesity, 6(6), 395-403.

11. Tran, V. D., James, A. P., Lee, A. H., Jancey, J., Howat, P. A., \& Thi Phuong Mai, L. (2017). Effectiveness of a community-based physical activity and nutrition behavior intervention on features of the metabolic syndrome: a clusterrandomized controlled trial. Metabolic syndrome and related disorders, 15(2), 63-71.

12. Graffagnino, C. L., Falko, J. M., La Londe, M., Schaumburg, J., Hyek, M. F., Shaffer, L. E., \& Caulin- Glaser, T. (2006). Effect of a communitybased weight management program on weight loss and cardiovascular disease risk factors. Obesity, 14(2), 280-288.

13. Afshin, A., Babalola, D., Mclean, M., Yu, Z., Ma, W., Chen, C. Y., \& Mozaffarian, D. (2016).
Information technology and lifestyle: a systematic evaluation of internet and mobile interventions for improving diet, physical activity, obesity, tobacco, and alcohol use. Journal of the American Heart Association, 5(9), e003058.

14. American psychological association. (2019). Mind/body health: Obesity. (Cited May 4, 2019). Available from https://www.apa.org/helpcenter/obesity

15. Hudson, J., Hiripi, E., Pope, H., Kessler, R. (2017). The prevalence and correlates of eating disorders in the National Comorbidity Survey Replication. Biological psychiatry, 61(3), 348-358. (Cited Aug 17, 2019). Available from https://

16. Davin, S. A., \& Taylor, N. M. (2009). Comprehensive review of obesity and psychological considerations for treatment. Psychology, health \& medicine, 14(6), 716-725.

17. Aryal, K. K., Mehata, S., Neupane, S., Vaidya, A., Dhimal, M., Dhakal, P., \& Garg, R. M. (2015). The burden and determinants of non-communicable diseases risk factors in Nepal: findings from a nationwide STEPS survey. PloS one, 10(8), e0134834.

18. World Health Organization. (2019). Global Physical Activity Surveillance. (Cited Aug 17, 2019). Available from https://www.who.int/ncds/surveillance/steps/GPAQ /en/

19. Raynor, H. A., \& Champagne, C. M. (2016). Position of the Academy of Nutrition and Dietetics: interventions for the treatment of overweight and obesity in adults. Journal of the Academy of Nutrition and Dietetics, 116(1), 129-147.

20. Stanszus, L. S., Frank, P., \& Geiger, S. M. (2019). Healthy eating and sustainable nutrition through mindfulness? Mixed method results of a controlled intervention study. Appetite, 104325. 